\title{
On the truss-type structures backing the ceramic tiles in the ballistic panels subjected to the impact of hard steel projectiles
}

\author{
A. Morka \& P. Dziewulski \\ ${ }^{1}$ Military University of Technology, Warsaw, Poland
}

\begin{abstract}
The objective of this paper is a feasibility study of a new concept for ceramic backing in multilayer ballistic panels. The truss structures were applied as a backing layer. They were based on a diamond crystal structure. The analysis of length/diameter ratio of the bars was performed. It was aimed at the achievement of the required mechanical properties maximizing the ballistic resistance and minimizing panel surface density. The panel structure is considered as a composition of $\mathrm{Al}_{2} \mathrm{O}_{3}$ ceramic tile backed by a plate in a truss form made of aluminum alloy or steel. These results were compared with classic multilayer solutions based on solid aluminum alloy backing plates. The study was carried out for a normal impact of the AP (armor-piercing) 7.62x51 projectile type with tungsten carbide (WC) core. A method of computer simulation was applied to study the problem. The Finite Element Method (FEM) implemented in the LSDYNA code was used. The full 3D models of the projectile and target were developed with strain rate and temperature-dependent material constitutive relations. The Johnson-Cook constitutive model with Gruneisen Equation of State (EOS) was applied to describe the behavior of metal parts: aluminum alloy and projectile's core. However, the Johnson-Holmquist model was used to describe the ceramic material. The Boundary Conditions (BC) were defined by supporting the panel at its back edges. The obtained results show the alternative solution to the classic solid plates supporting the ceramic layers in ballistic panels. It was identified that the main deformation mechanism in truss-type backing components is buckling if the L/D ratio goes up. A virtual prototyping technique could be applied to manufacture the developed truss structure.
\end{abstract}

Keywords: computational mechanics, finite element method, ballistic protection, multilayer armour, ceramic armour systems, truss structure. 


\section{Introduction}

Modern ballistic protection systems, especially for light-weight armored vehicles, are based on the multilayer armour concept, fig. 1 [11]. The main task to resist the projectile is typically given a ceramic layer. However, the ceramic material is known as very brittle so its strength in tension or bending loads is very low. Therefore, the next layer behind should compensate for this disadvantage of the ceramics. It is known as a backing effect. The solid materials like aluminum or polymer composite are considered as the backing plate in classic solutions of ballistic panels. The surface density of the panel is a crucial parameter at given effectiveness, and then its minimization is especially important. There is no alternative to ceramics in case of Armour Piercing (AP) projectiles containing hard cores made of steel or tungsten alloys. Then the backing plate can be considered to be replaced with a lighter material. One possibility is a choice of a truss structure. However, selection of the best structure is not a simple task. So we turned to nature in looking for a hint. The answer came from space. It could be lonsdaleite; in other words hexagonal diamond. Its crystal structure is an allotrope of carbon with hexagonal lattice. It is formed in nature when graphite-containing meteorites strike the Earth. The great heat and pressure of the impact transforms the graphite into diamond, but retains graphite's hexagonal crystal lattice. Lonsdaleite was first identified from the Canyon Diablo meteorite, where it occurs as microscopic crystals associated with diamond. It was first discovered in nature in 1967 [4]. Specific gravity of 3.2 to 3.3, and Mohs hardness of 7-8 [5]. The Mohs hardness of diamond is 10, and the lower hardness of lonsdaleite is chiefly attributed to impurities and imperfections in the naturally-occurring material. Numerical analysis showed that pure sample has been found to be $58 \%$ harder than diamond [6]. Lonsdaleite is expected to be $58 \%$ harder than diamond and to resist indentation pressures of $152 \mathrm{GPa}$, whereas diamond would break at $97 \mathrm{GPa}[6]$.

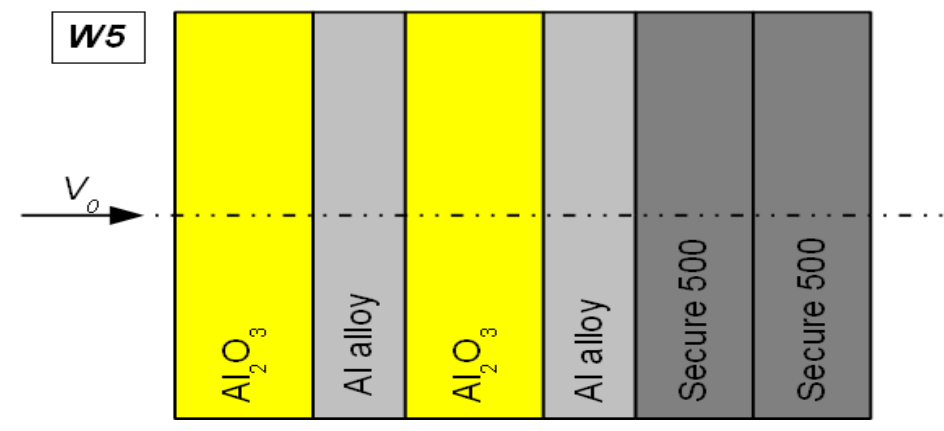

Figure 1: $\quad$ An example of the multilayer armour concept [11].

The authors do not intend to apply such rare and strange material as the backing plate in ballistic panels. The truss structure in demand could be based on the lonsdaleite's crystal lattice instead. The main idea is that the very high 
hardness of this crystal may partially be a result of its specific crystal structure. It is clear that the real truss structure cannot reproduce the atomic forces of interaction, where the force is proportional to the square of displacement. In contrast, for macroscopic materials, the Hook's law yields only the linear relation between force and displacement. However, it is still interesting to know the role of the geometric factor in overall structure strength. The truss structure formed as a plate is presented in fig. 2 with different points of view. The characteristic size of the elementary cell is around $0.45 \mathrm{~mm}$.

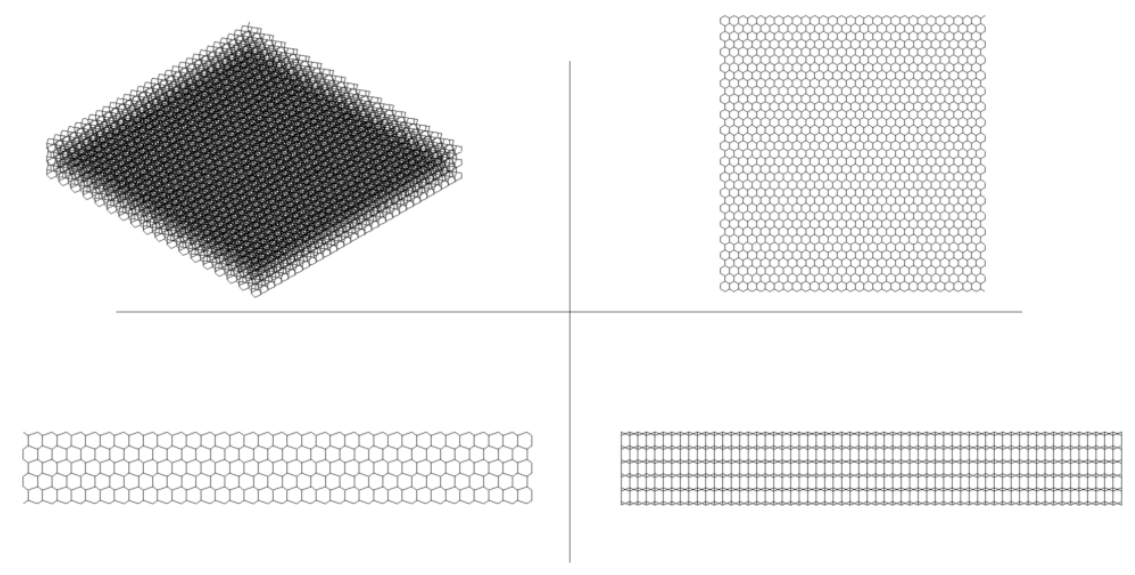

Figure 2: A truss structure formed based on an idea of the lonsdaleite's crystal lattice.

\section{Description of the problem}

An assessment of the effectiveness of the truss-type backing plate is performed by comparison with other standard solutions. Several cases are considered: (1) the absence of the backing plate, (2) rigid backing plate with friction, (3) solid aluminium plate supporting the ceramics and, finally, (4) truss structure covered by two thin aluminium alloy sheets applied as the backing of the ceramic tile. The test problem was selected as a normal impact of the AP (armorpiercing) $7.62 \times 51 \mathrm{~mm}$ projectile type with WC core on $9 \mathrm{~mm}$ thick hexagonal ceramic tile supported by one of the above-mentioned ways. The dimensions of the projectile and targets were depicted in fig 3 . The structure of this projectile type is complex, but the tungsten carbide core plays the main role in perforation process. Then the problem was simplified to describe only $\mathrm{WC}$ core dynamics. The experimental tests were conducted for $10 \mathrm{~mm}$ thick $\mathrm{Al}_{2} \mathrm{O}_{3}$ ceramic tile backed by PA11 aluminum alloy disc with thickness of $10 \mathrm{~mm}$. The final result is shown in fig. 4, where the deformed backing plate is visible. It is important to note that such configuration of the ballistic panel is effective enough to stop the $7.62 \times 51 \mathrm{~mm}$ AP projectile. 
The quantitative results assessment should be based on the independentlymeasured parameters. They are supposed to include the time history of the projectile kinetic energy (PKE) and residual length of the projectile (RLP). However, the qualitative evaluation is going to be based on the projectile/target deformation at a selected moment of time after impact.
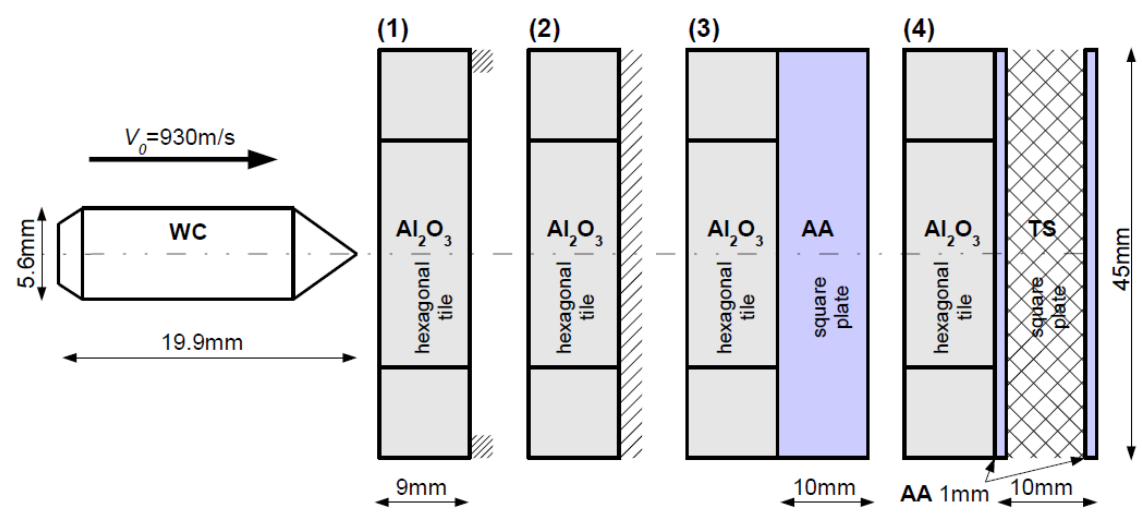

Figure 3: The dimensions of the projectile and the target configurations in the test problem.

a)

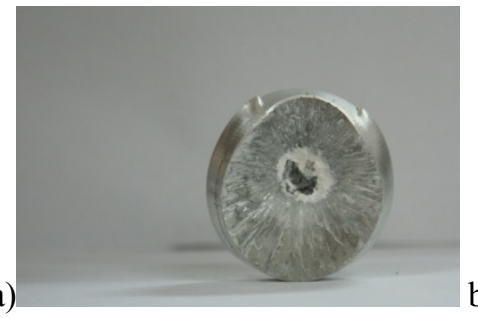

b)

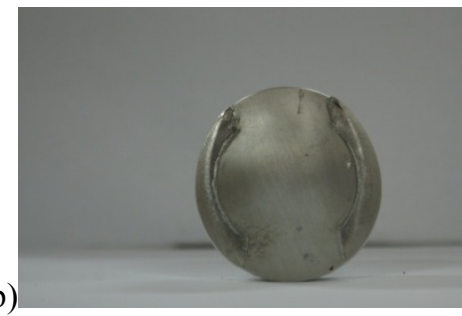

Figure 4: The result of the experimental impact test for the system of 10/10 mm thick $\mathrm{Al}_{2} \mathrm{O}_{3}$ ceramic tile backed by disc of PA11 aluminum alloy, (a) front, (b) back view. The projectile was the $7.62 \times 51 \mathrm{~mm}$ AP with WC core, initial velocity: $921 \mathrm{~m} / \mathrm{s}$.

\section{Description of the numerical model}

A method of computer simulation was applied to study the problem. The Finite Element Method (FEM) implemented in the LS-DYNA commercial code was used with explicit (central difference) time integration algorithm [3]. 
The full 3D models of the projectile and target were developed with a strain rate and temperature-dependent material constitutive relations. The JohnsonCook constitutive model with Gruneisen Equation of State (EOS) was applied to describe the behavior of the metallic parts: aluminum alloy and projectile's core, table 2. However, the Johnson-Holmquist ( $\mathrm{JH} 2)$ model was used to describe the ceramic material $\mathrm{Al}_{2} \mathrm{O}_{3}$, table 1 . Besides, the truss components were modeled as a bilinear elastic-plastic material with the typical elastic parameters for aluminum alloy (AA) or steel supplied with yield stress and hardening modulus: $350 \mathrm{MPa}, 7 \mathrm{GPa}$ and $1.25 \mathrm{GPa}, 20 \mathrm{GPa}$ respectively for AA and steel. Generally, the failure model based on the effective plastic strain was applied, but the $\mathrm{JH} 2$ describes the damage evolution and even completely failed ceramics. In this case, the given effective plastic threshold (150\%) was used to limit the excessive finite elements deformations which can lead to numerical errors like negative volume.

The Boundary Conditions (BC) were defined by supporting the panel at its back edges at a distance of $4.5 \mathrm{~mm}$. It was numerically realized by frictional contact with a rigid body and a friction coefficient of 0.5 was assumed. The initial conditions were limited to the given initial projectile velocity, $930 \mathrm{~m} / \mathrm{s}$.

A spatial problem discretization was conformed to available computing resources. The projectile (WC core) mesh was built of the tetrahedronal elements with one integration point sized from $0.1 \mathrm{~mm}$ at the sharp head to $0.5 \mathrm{~mm}$ elsewhere. Similar mesh topology was selected for the hexagonal ceramic tile, but its density gradually grows in the direction of the location of the impact point. Characteristic single element length varies from 1 to $0.5 \mathrm{~mm}$. The solid components of the backing plate were divided into constant stress brick finite elements with a typical size of $0.5 \mathrm{~mm}$. Finally, the numerical representation of the truss structure was built with an application of 1D beam elements. A total number of beam elements exceeded 500k with a single beam length of 0.1$0.15 \mathrm{~mm}$. Summarizing the mesh configuration of the studied problem, it comes up in one million elements.

Table 1: Johnson-Holmquist constitutive model constants for alumina [9].

\begin{tabular}{ccc}
\hline Parameter & Units & High purity $\mathbf{A l}_{\mathbf{2}} \mathbf{O}_{\mathbf{3}}$ \\
\hline $\mathbf{J H}-\mathbf{2}$ & & {$[7]$} \\
\hline$\rho$ & $\mathrm{kg} / \mathrm{m}^{3}$ & 3840 \\
$A$ & & 0.88 \\
$B$ & & 0.45 \\
$C$ & & 0.007 \\
$m$ & & 0.6 \\
$n$ & & 0.64 \\
$T$ & $\mathrm{GPa}$ & 0.462 \\
$H E L$ & $\mathrm{GPa}$ & 7.0 \\
$D_{1}$ & & 0.0125 \\
$D_{2}$ & & 0.7 \\
$F S$ & & 1,5 \\
\hline $\mathrm{EOS}$ & & \\
\hline$k_{1}$ & $\mathrm{GPa}$ & 231 \\
$k_{2}$ & $\mathrm{GPa}$ & -160 \\
$k_{3}$ & $\mathrm{GPa}$ & 2774 \\
\hline
\end{tabular}


Table 2: Johnson-Cook constitutive model, failure model and Gruneisen Equation of State data for WC and aluminum alloy materials [9].

\begin{tabular}{cccc}
\hline Parameter & Units & 93\%WC6\%Co & AA2024-T3 \\
\hline Johnson -Cook & & {$[9]$} & {$[10]$} \\
\hline$A$ & GPa & 3 & 0.369 \\
$B$ & GPa & 89 & 0.684 \\
$C$ & - & 0 & 0.0083 \\
$m$ & - & 1 & 1.7 \\
$n$ & - & 0.65 & 0.73 \\
\hline Gruneisen & & & \\
Equation of State & & 5210 & 5328 \\
\hline$c$ & $\mathrm{~m} / \mathrm{s}$ & 1.14 & 1.338 \\
$S_{1}$ & - & 0 & 0 \\
$S_{2}$ & - & 0 & 0 \\
$S_{3}$ & - & 1 & 2 \\
$\Gamma_{0}$ & - & 0 & 0.48 \\
$a$ & - & & \\
\hline Failure & & 0.03 & 1.67 \\
\hline$D_{1}(\mathrm{JC})$ & - & 2.7 & \\
$P C(\mathrm{spall})$ & $\mathrm{GPa}$ & &
\end{tabular}

\section{Analysis of the results}

The truss type backing plate effectiveness was studied according to the assumptions mentioned earlier. The numerical results of the computer simulations of the impact test problem were mutually compared. The qualitative evaluation was performed by comparison of the projectile/target deformation at selected moment of time after impact. Figs. 5 and 6 present these results where the targets were crossed and half of them were removed from view for better interpretation. Two characteristic stages of the panel perforation process were chosen: $10 \mu \mathrm{s}$ when the projectile reaches the middle surface of the ceramic tile the most resisting stage during impact, and $20 \mu$ s when the ceramic layer is completely defeated and the projectile starts to perforate the backing plate - this stage describes the progressive loss of the panel's resisting properties. The careful examination of these images lets us form the conclusion that the backing effect is very important in overall ballistic panel effectiveness and the perfect stiff support gives the best result, solid backing plates are seemed to be more realistic, preserving quite an acceptable level of functionality. And finally, the truss based backing structures appear quite efficient but are unbeatable if compared with the surface mass density. 
coo

a)

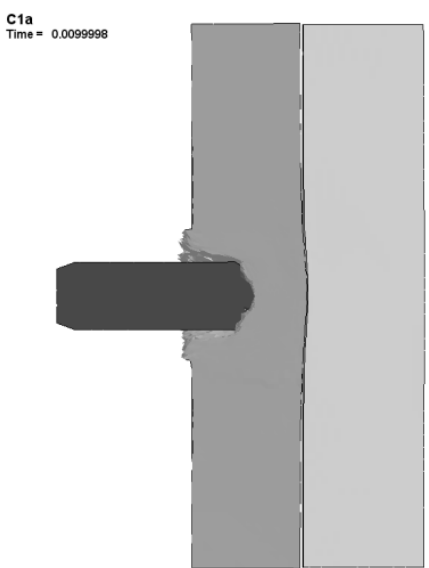

c)
Co0a
Time $=$
0.01

b)

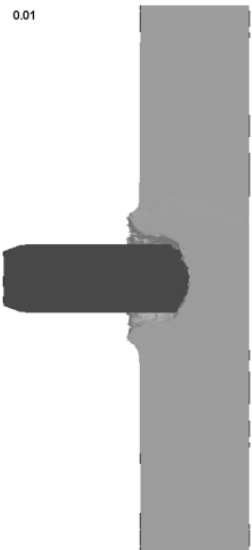

cla

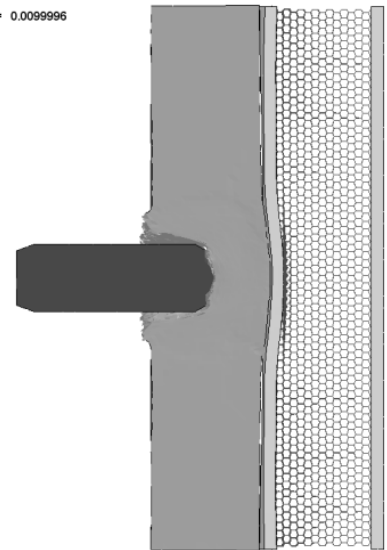

d)

Figure 5: The images of the projectile/target deformation at $10 \mu \mathrm{s}$ after impact for studied cases where the following were applied as the backing plate: (a) none, (b) rigid body, (c) solid AA, (d) truss structure. 

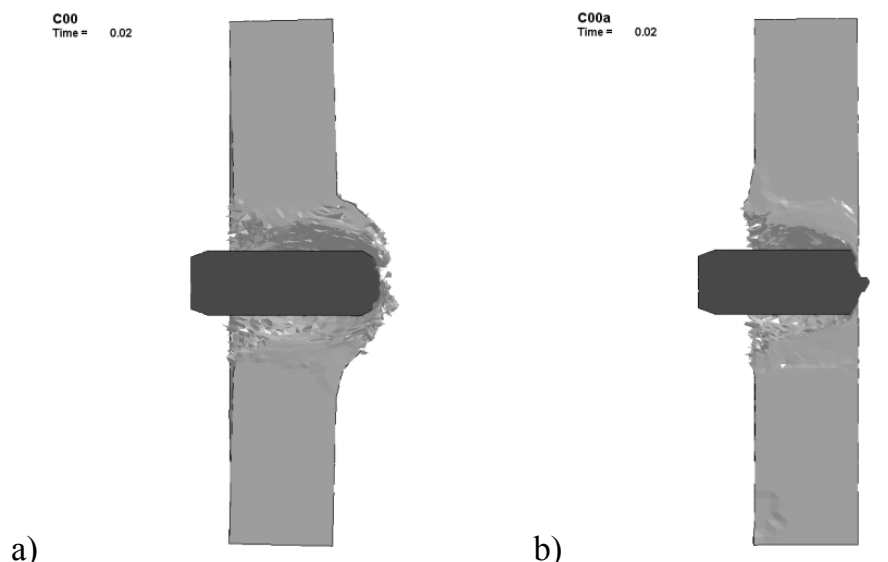

$\underset{\substack{\text { cha } \\ \text { Time }}}{\operatorname{an}}=0.02$

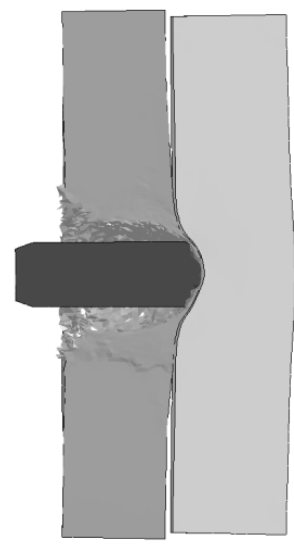

$\underset{\substack{\text { Cia } \\ \text { Time }}}{\mathrm{C}}=0.02$

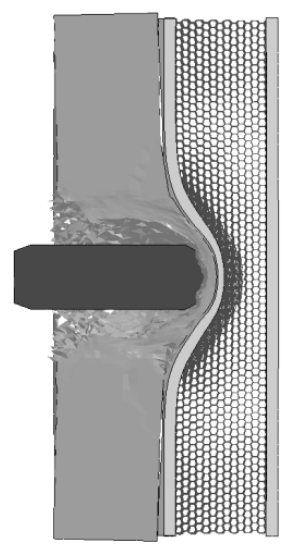

d)

Figure 6: The images of the projectile/target deformation at $20 \mu \mathrm{s}$ after impact for studied cases where the following were applied as the backing plate: (a) none, (b) rigid body, (c) solid AA, (d) truss structure.

The quantitative assessment was carried out by comparison of the specific problem parameters. These are the time history of the projectile kinetic energy (PKE), fig. 7, as well as the residual length of the projectile (RLP), table 3 . The rigid support of the ceramic layer ensures the most efficient dissipation of the projectile kinetic energy and leads to its shortest residual length. Unfortunately, it is an unrealistic case and substitute solutions have to be considered as the solid or truss-type plates backing the ceramic tiles. Both of them mutually confronted proved sufficient and effective in providing the global panel resistance. Additionally, the mass effectiveness presented in table 3 emphasises the advantages of the truss-type backing solutions. 
Table 3: The Residual Length of the Projectile (RLP) and the minimal identified PKE as functions of the single truss characteristics (L/D, material type).

\begin{tabular}{ccccc}
\hline Backing type: & L/D & $\begin{array}{c}\text { Panel surface } \\
\mathbf{d e n s i t y} \\
{\left[\mathbf{k g} / \mathbf{m}^{2}\right]}\end{array}$ & $\begin{array}{c}\text { Minimum PKE, } \\
\mathbf{t}=\mathbf{5 0} \boldsymbol{\mu s} \\
{[\mathbf{J}]}\end{array}$ & $\begin{array}{c}\text { Residual Length } \\
\text { of the Projectile } \\
{[\mathbf{m m}]}\end{array}$ \\
\hline none & - & 34.2 & 1721 & 16.5 \\
rigid body & - & 34.2 & 637 & 14.2 \\
AA & - & 61.2 & 390 & 16.0 \\
AA truss structure & 3 & 44.7 & 1159 & 16.3 \\
& 5 & 41.5 & 1360 & 16.5 \\
steel truss structure & 3 & 40.2 & 1443 & 16.5 \\
\hline
\end{tabular}

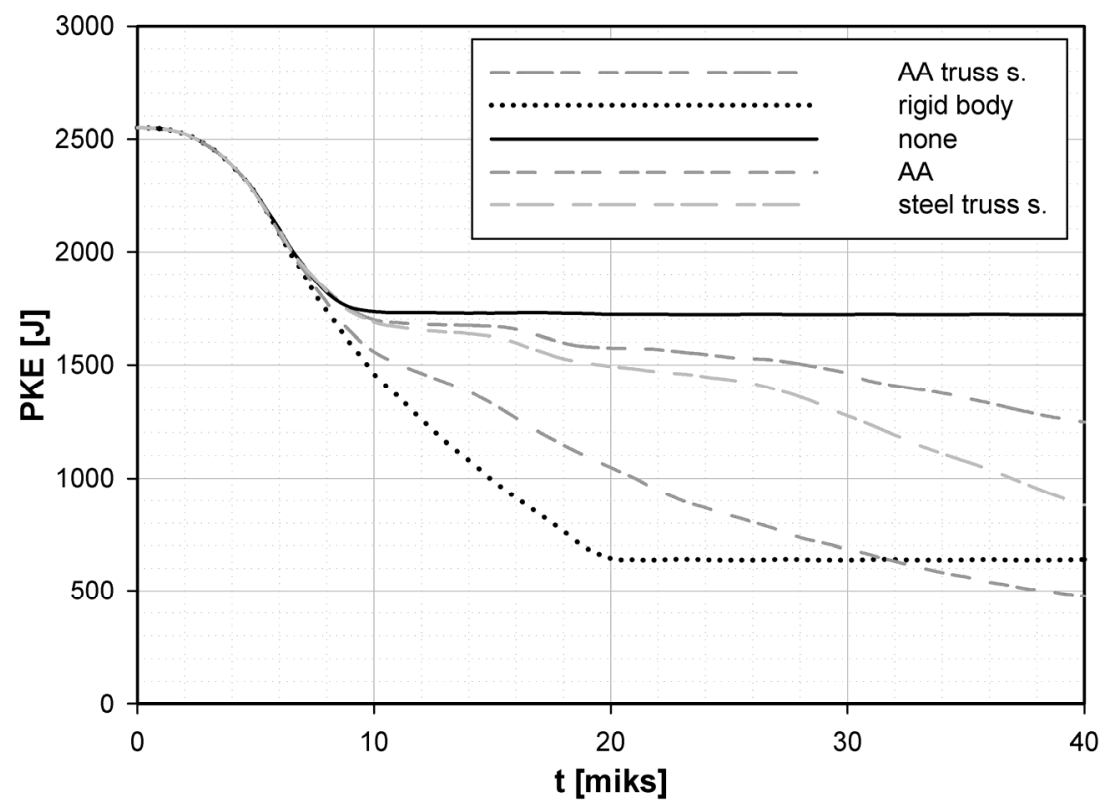

Figure 7: The time histories of the projectile kinetic energy (PKE) for studied cases.

\section{Conclusions}

The obtained results show that the satisfactory level of the ballistic protection may be accomplished by application of the truss type backing plates with preserving very low surface density of the panel. The hexagonal crystal lattice of 
the lonsdaleite was used as an idea to build the studied truss-type plate successfully. It may be interesting to compare the efficiency of this structure with other concepts like honeycomb or Kelvin structure (tetradecahedron). The improvement in backing effectiveness was observed with scaling down the single truss ratio L/D. It was identified that the main deformation mechanism in truss-type backing components is buckling if the $\mathrm{L} / \mathrm{D}$ ratio goes up. A virtual prototyping technique could be applied to manufacture the developed truss structure to confirm its properties in experimental impact tests.

\section{Acknowledgement}

The paper is supported by Grant No. O R00 0056 07, financed in year 2009-2011 by the Ministry of Science and Higher Education, Poland.

\section{References}

[1] Johnson, G.R., Cook, W.H., A Constitutive Model and Data for Metals Subjected to Large Strains, High Strain Rates and High Temperatures. Proc. of the 7th International Symposium on Ballistics: Hague, Netherlands, 1983.

[2] Kury, W.J., Breithaupt, D., Tarver, M.C., Detonation Waves in trinitrotoluene. Shock Waves, 9(2), pp. 227-237, 1999.

[3] Hallquist, J.O. (compiled), LS-Dyna Theory Manual, Livermore Software Technology Corporation (LSTC), 2006.

[4] Frondel, C., Marvin U.B., Lonsdaleite, a new hexagonal polymorph of diamond. Nature, 214, pp. 587-589, 1967.

[5] The mineral and locality database, www.mindat.org/min-2431.html

[6] Pan, Z., Sun, H., Zhang, Y., Chen, Ch., Harder than Diamond: Superior Indentation Strength of Wurtzite BN and Lonsdaleite. Physical Review Letters, 102(102), 2009.

[7] Tasdemirci, A., Hall I.W., Numerical and experimental studies of damage generation in multi-layer composite materials at high strain rates. International Journal of Impact Engineering, 34, pp. 189-204, 2007.

[8] LS-DYNA Keyword User's Manual, version 971, Livermore Software Technology Corporation (LSTC), 2007.

[9] Holmquist, T.J., Johnson G.R. \& Gooch, W.A., Modeling the $14.5 \mathrm{~mm}$ BS41 projectile for ballistic impact computations, Computational Ballistics II, Transaction: Modelling and Simulation volume 40, pp. 61-75, 2005.

[10] Panov, V., Modelling of behaviour of metals at high strain rates, Cranfield University, PhD Thesis, 2005.

[11] Morka, A., Zduniak, B., Niezgoda, T., Numerical Study of the Armour Structure for the V+ Ballistic Protection Level according to STANAG 4569, transl. from Polish, Technical Report PBN 03-433/2010/WAT, AMZKutno, Poland, 2010. 